Universidad de Guadalajara

Derecho Global. Estudios sobre Derecho y Justicia

Año 3, núm 9, julio-octubre, 2018, pp.13-36, ISSN: 2448-5128 e-ISSN: 2448-5136

https://doi.org/10.32870/dgedj.v0i9.164

\title{
Los derechos inderogables del accionista en la sociedad anónima como derechos mínimos fundamentales y los derechos instrumentales
}

\section{The non-derogable rights of the shareholder in the corporation, such as fundamental minimum rights and instrumental rights}

Recibido: 11/12/2017

Soyla H. León Tovar

Investigadora de la Universidad Panamericana. México

Aceptado: 05/01/2018

soleon@up.edu.mx

RESUMEN: Objetivo: Este artículo aborda el tema de los derechos mínimos fundamentales del accionista de la sociedad anónima. Exposición. Se analizan los derechos del accionista desde la doctrina, la legislación comparada y la jurisprudencia, así como sus clasificaciones y evolución. Hallazgos. Con la codificación del derecho mercantil, se reconocieron diversos derechos al accionista, pero desde finales del siglo pasado, algunas legislaciones autorizan la supresión, alteración o suspensión de algunos de ellos, lo que ha generado una crisis en el concepto de accionista y de sus derechos mínimos. Discusión. La doctrina debate sobre el carácter inderogable de algunos derechos de los accionistas, por lo que en este artículo se propone una clasificación que considera los derechos instrumentales del accionista. Conclusión. No existe consenso en la doctrina ni en la legislación comparada sobre los derechos mínimos fundamentales del accionista. Es necesario identificar esos derechos para evitar abusos en la sociedad anónima

PALABRAS CLAVE: accionistas, sociedad anónima, derechos de los accionistas. derecho de voto.

ABSTRACT: Objective: This article addresses the minimum fundamental rights of the shareholder of the corporation. Exposition. The rights of the shareholder are analyzed from the doctrine standpoint, comparative legislation and jurisprudence, as well as their classification and evolution. Findings. With the codification of commercial law, various rights were recognized to the shareholder, but since the end of the last century, some laws authorize the suppression, alteration or suspension of some of them, which has generated a crisis in the concept of shareholder and their minimal rights. Discussion. The doctrine discusses the non-derogable nature of some rights of shareholders. This article proposes a classification that considers the instrumental rights of the shareholder. Conclusion. There is no consensus in the doctrine or in the comparative legislation on the fundamental minimum rights of the shareholder. It is necessary to identify those rights to avoid abuses in the corporation.

KEY WORDS: shareholders, corporation, shareholders' rights, right to vote. 


\section{SUMARIO}

I. Introducción. II. Estatutos de accionista de la sociedad anónima. III. Perspectiva histórica delos derechos de accionista. IV. Clasificación de los derechos de accionista; IV.1 Clasificación por su contenido; IV.2 Clasificación por la naturaleza de los derechos; V. Nueva clasificación de los derechos de los accionistas. V.1 Derechos esenciales o instrumentales del accionista V.2 Derechos mínimos fundamentales o inderogables. V.3 Derechos disponibles VI. Conclusiones. Bibliografía.

\section{Introducción}

Con la consolidación de los Estados nacionales, la sociedad anónima (S.A.) se configura como una sociedad democrática en la que sistemáticamente los accionistas tienen derecho a participar en la asamblea con un voto por acción, no existen acciones sin voto ni de voto plural, las resoluciones se adoptan bajo el principio de mayoría y se acuñan diversos derechos como inderogables (voto, asistencia y participación en las utilidades); sin embargo, diversos fenómenos económicos y jurídicos han hecho crisis en el concepto de sociedad y de socio; el abstencionismo, la sociedad unipersonal, la desregulación y flexibilización societarias, las clases de acciones y en general la huida del derecho societario al contractual, y han puesto en riesgo los derechos inderogables del accionista y las bases fundamentales de estos; lo que se analiza en este trabajo a partir del carácter de accionista, la evolución del reconocimiento de sus derechos, las clasificaciones sobresalientes y la necesidad de optar por una nueva clasificación como la que se expone en la que se reconozcan los derechos mínimos fundamentales y los inderogables de todo accionista que impidan el abuso de la mayoría.

\section{Estatutos de accionista de la sociedad anónima}

Ser accionista no significa ser titular de la sociedad ni de su empresa o patrimonio, aunque la sociedad se constituya con un único socio, es un sujeto de derecho 
distinto con patrimonio propio que no puede confundirse con el de los accionistas aunque éstos hayan aportado e integrado el capital social, pues con ello solo adquieren el estatus o calidad de accionista que es una situación jurídica por la cual es titular de un conjunto de derechos en la sociedad, una cualidad o posición subjetiva y compleja que le permite, según el monto y clase de acciones de que sea titular, tener injerencia en el ente social (Barrera Graf, 1983, pág. 19), integrar la voluntad social en la asamblea general, constituir los órganos sociales y adquirir un conjunto de derechos y deberes corporativos y patrimoniales (Castro Ossandon, 1985, pág. 14), algunos de los cuales no pueden ser alterados por la sociedad. Dicho estatus se adquiere de forma originaria desde el momento en el que suscribe cuando menos una acción (Pérez Fontana, 1983, pág. 109) o por asignación de ésta en virtud de capitalización de pasivos, fusión o escisión, o de manera derivada por la adquisición de acciones a otro accionista (Duque Domínguez, 1994, pág. 35) (Barrera Graf, 1983, pág. 79) (Tobío Rivas, 1995, pág. 19).

\section{Perspectiva histórica de los derechos de accionista}

El surgimiento de las sociedades comerciales precursoras de la S.A. no trajo consigo el derecho de intervenir en la gestión social, las Maone del siglo XII y la "Società delle Compere e dei Banchi di San Giorgio" (Malagarriga, 1951, pág. 390 y 391) (Tobío Rivas, 1995, pág. 19), únicamente concedían derecho a las utilidades (Fernández Villamayor, 1978) y, aunque sociedades como la Compañía Holandesa de las Indias Orientales (Brunetti) otorgaron el derecho a designar administradores (Garrigues, 1981, pág. 24 y 25), hasta 1642 con las compañías francesas se reconoció el derecho de aprobar las cuentas de los administradores y deliberar sobre los resultados obtenidos, aunque la distribución se hacía por órdenes del rey, quien también nombraba a los directores y presidía las asambleas.

Con la regulación de la S.A. en los Códigos de Comercio del siglo XIX, se reconocen el derecho de voto del accionista como inderogable esencial, absoluto y proporcional a la participación social (Messineo, 1955, pág. 400), el derecho de participar en las utilidades, el de cuota de liquidación y el de suscripción 
preferente; derechos que desde entonces han configurado el estatus de socio de la S.A. y solo de manera excepcional habían sido alterados o suprimidos, como el del voto para impedir la paralización de las asambleas ante la ausencia de accionistas de inversión (a quienes lo único que les importa es su participación en las utilidades de la sociedad). Tales derechos han sido clasificados de diversas formas por la doctrina.

\section{Clasificación de los derechos de accionista}

La S.A. es una sociedad capitalista, los derechos del socio se determinan en función del número de acciones que suscribe y su responsabilidad se limita al pago de su aportación sin responder por las deudas sociales ni contraer otras obligaciones de dar, hacer o no hacer; como miembro del ente social, el accionista aporta recursos para un fin común, causa eficiente de su aportación que es la de participar en las utilidades del negocio o empresa sociales y en su caso asumir las pérdidas hasta el monto de su aportación. Por tanto, la participación en las utilidades de la sociedad es uno de los derechos mínimos que el accionista espera tener en la sociedad, aunque ese derecho mínimo individual esté en tensión con los derechos de la sociedad o de la mayoría que se niegan a distribuir utilidades; así que surge el problema de saber hasta dónde la asamblea por mayoría de votos puede decidir siempre y hasta en estatutos privar a los socios de utilidades, distribuirlas cada cierto periodo o no hacerlo, cuándo existe abuso de la mayoría sobre la minoría o el chantaje de ésta sobre aquélla, para ello, es necesario determinar los derechos mínimos que le corresponden a cada accionista y los derechos instrumentales con base en los cuales puede hacer efectivos los primeros.

\section{IV.1 Clasificación por su contenido}

La mayoría de la doctrina ha clasificado los derechos de los accionistas en dos grandes grupos: a) patrimoniales o económicos y b) políticos, corporativos, administrativos (Tobío Rivas, 1995, pág. 20) o de consecución (Galgano, 1984, pág. 147) (Rubio, 1974, pág. 330); los primeros como derechos de contenido económico, susceptibles de alterarse o modificarse que pueden ser (Rodríguez 
Rodríguez, 1982, pág. 54) : i) principales (dividendo y cuota de liquidación) y ii) accesorios (transmisión de la calidad de socio y título accionario). Los derechos corporativos o de consecución, en cambio, según la doctrina son derechos no susceptibles de alterarse, confieren al accionista el derecho a participar en la gestión social, en la administración de manera directa o indirecta y para obtener la realización de actos que le permitan el ejercicio de otros derechos (Mantilla Molina, 1996, pág. 224). Rodríguez distingue dentro de estos derechos a los derechos administrativos (participación en las asambleas; nombramiento de administradores; aprobación del balance -estados financieros) y los de vigilancia (aprobación de balance y de las gestiones de los administradores; determinación de emolumentos y, nombramiento de comisarios e interventores, denuncia a los comisarios, derechos de impugnación de los acuerdos sociales y, el derecho de suspender las ejecuciones de los acuerdos).

\section{IV.2 Clasificación por la naturaleza de los derechos}

Esta segunda clasificación doctrinal, atiende a la naturaleza de los derechos: a) derechos inderogables (Garrigues, 1981, pág. 518), indisponibles o irrevocables; b) derechos irrenunciables; y, c) derechos renunciables.

\section{a) Derechos inderogables}

También denominados indisponibles o irrevocables, son derechos que le corresponden al accionista por tener tal carácter, que no se pueden suprimir o derogar por la sociedad porque provienen de una norma ius cogen; como los derechos a las utilidades, voto, asistencia, suscripción preferente, información y agrupación; conforme la Ley General de Sociedades Mercantiles (LGSM) antes de la reforma del 13 de junio de 2014, tienen tal carácter los siguientes, si bien algunos de ellos ya no son inderogables:

1. Derecho de convocatoria a las asambleas generales, y en su caso a las especiales cuando constituyan minoría o sean titulares de una clase especial de acciones (artículos 168, 184, 185, 186 y 187 LGSM).

2. Derecho de asistencia a las asambleas generales y en su caso especiales; con independencia de que la LGSM exija un quórum mínimo de asistencia a las 
asambleas generales en función de las acciones con derecho a voto (artículos 91, fr. VII, 181, 182, 188, 189 LGSM).

3. Derecho de deliberación, del que gozan los accionistas para exponer los motivos por los cuales consideran que una resolución debe o no ser adoptada por la asamblea, salvo que el accionista tenga interés opuesto al de la sociedad (artículos 181, 182, 188, 189 y 196 LGSM); este derecho ya no es inderogable, sigue la suerte del derecho de voto.

4. Derecho de voto, del que gozan los titulares de las acciones, un derecho irrestricto de votar a favor o en contra de las resoluciones de la asamblea o de abstenerse de hacerlo, con las limitaciones impuestas para cada clase de acción (artículos 112 y 113 LGSM); actualmente, con la admisión de acciones sin derecho de voto, de voto restringido y de voto limitado, este derecho es absolutamente disponible.

5. Derecho de representación, derecho inderogable que no se puede suprimir al accionista (artículo 92).

6. Derecho de información (artículo 173 LGSM).

7. Derecho de participación en las utilidades (derecho al dividendo), con las preferencias o privilegios o sin ellos e incluso con las limitaciones ahora permitidas, todos los accionistas tienen derecho de participar en los dividendos de la sociedad proporcionalmente a sus aportaciones exhibidas o conforme lo previsto por los estatutos (artículos 16, 17, 19, 112 y 117 LGSM).

8. Derecho de suscripción preferente de nuevas acciones a pagarse con nuevas aportaciones (artículos 132 LGSM), salvo en acciones convertibles en acciones (artículo 210 y ss. LGTOC); este derecho actualmente ya no es inderogables, los estatutos sociales pueden establecer su supresión, suspensión o limitación (artículo 91, fracción VII) y además es un derecho disponible por el accionista mediante pactos parasociales (artículo 198 LGSM).

9. Derecho asignación gratuita de acciones emitidas en virtud de fusión, escisión o aumento del capital por capitalización de reservas de valuación, 
revaluación, de utilidades distribuibles y de primas de acción; en la proporción de las exhibiciones realizadas por sus acciones (artículo 116 LGSM).

10. Derecho a la cuota de liquidación (artículos 248 y 249 LGSM).

11. Derecho de transmitir las acciones (a. 111, 124, 125 y 130 LGSM), aunque la LGSM autoriza a la sociedad a establecer en los estatutos sociales, y a los socios en pactos parasociales, limitaciones de cualquier naturaleza, pero no a suprimirlo, salvo en el caso de las acciones de trabajo que la ley autoriza a la sociedad a determinar las normas respecto de su inalienabilidad.

12. Derecho de igualdad respecto de los accionistas de la misma clase, comunes, preferentes o privilegiados (a. 112 LGSM), subordinadas; y,

13. Derecho de agrupación en minoría o mayoría (a.113, 144, 163, 164, 184, 199 y 201 LGSM); y,

14. Derecho de impugnación (arts. 87, 205 LGSM)

b) Derechos irrenunciables

Según la doctrina (Duque Domínguez, 1994, pág. 64), son los derechos que no se pueden suprimir ni por acuerdo mayoritario, ni con el consentimiento o voluntad del accionista, no son disponibles por éste ni a favor de la sociedad o de tercero porque son concedidos en su interés y en interés de la propia sociedad y son esenciales para su tipología social (De la Cámara Álvarez, 1997, pág. 572), como el derecho a impugnar acuerdos. Estos derechos encuadran dentro de los inderogables, cuya característica es que precisamente no son renunciables.

Conforme la LGSM (antes de la reforma) y la mayoría de la doctrina, son derechos irrenunciables los derechos de: convocatoria, asistencia, deliberación, voto e impugnación, mismos de los que no puede renunciar el accionista y conserva aún y cuando no haga uso de ellos o haya convenido con otros socios sindicar sus acciones o designado representante para asistir a las asambleas. Para Tobío Rivas, son derechos de esta naturaleza los derechos de voto, de impugnar acuerdos, de dividendo, de representación y de separación (Tobío Rivas, 1995, 
pág. 2). Para Vicent Chuliá tienen tal carácter los derechos de asistencia, representación, información, voz y voto (Vicent Chuliá, 1991, pág. 484), porque una vez concedidos no es posible que puedan ser derogados o suprimidos por la sociedad, pero pueden ser objeto de enajenación a cambio de dividendo (PazAres Rodríguez J. C., 1996, pág. 185).

c) Derechos renunciables

Son derechos renunciables para Girón Tena el derecho de separación y el de representación (Girón Tena, 1952, pág. 185), de la Cámara incluye el derecho de voto y los identifica como los que pueden ser influidos de alguna manera por los estatutos sociales en cuantía de su extensión y su contenido (De la Cámara Álvarez, 1997, pág. 572). Vicent Chuliá sostiene que solo son renunciables los derechos de contenido esencialmente patrimonial, aunque envuelvan una posición política del socio, como los de suscripción preferente (Vicent Chuliá, 1991, pág. 484 y 485). Son derechos concedidos a los socios en lo individual o colectivamente por la ley, con independencia de que los estatutos sociales lo prevean o no, porque, aunque no pueden ser dispuestos por la asamblea (derechos indisponibles), los accionistas pueden renunciar de manera total o parcial. Son derechos indisponibles porque la asamblea no puede revocar, suprimir o alterar si no cuenta con el consentimiento del titular, entre ellos: el derecho al dividendo preferente, el derecho a la cuota de liquidación (para cambiar la proporción a la aportación), el derecho de retiro (temporalmente), el derecho de transmitir o gravar las acciones (temporalmente), el derecho de voto, el de nombrar representante en la asamblea, el derecho de opción o preferencia; derechos que para algunos son identificados como individuales, sustraídos de la soberanía de la asamblea general que solo pueden ser modificados con el consentimiento del socio (Garrigues, 1981, pág. 25).

Para Sánchez Andrés (Sánchez, 1984), desde la regulación contenida en el art. 48 de la derogada LSA española, los derechos de voto y de suscripción preferente son suprimibles, mientras que el de información o el de asignación gratuita de acciones no pueden derogarse por ser derechos de miembro o de socio. 


\section{Nueva clasificación de los derechos de accionista}

Con la desregulación societaria, diversas legislaciones pusieron en predicamento los derechos inderogables de los socios, en México, la reforma del 13 de junio de 2014 a la LGSM, convirtió derechos inderogables en derogables y disponibles como el voto y el de suscripción preferente; pero subsisten otros derechos inderogables y mínimos fundamentales de todo accionista que deben delimitarse para mantener la figura del accionista y la naturaleza de la S.A., los cuales no se identifican ni fundamentan con las actuales clasificaciones de los derechos del accionista, ni con su contenido y naturaleza porque los corporativos sí tienen un valor económico y algunos derechos no pueden ser clasificados en corporativos o económicos, porque envuelven ambas categorías, como el derecho de igualdad; por lo que es necesaria una nueva clasificación que sin ser arbitraria ni caprichosa responda a diversos cuestionamientos esenciales sobre los derechos, la medida y extensión en que pueden los estatutos sociales o la asamblea de accionistas, suprimir, limitar, ampliar o suspender sin transfigurar el tipo social ni el carácter de socio de una S.A.; tales cuestionamientos pueden ser: ¿Existen derechos de accionista que no se pueden alterar o derogar ni con el consentimiento del accionista?, ¿Qué derechos pueden ser suprimidos, suspendidos o limitados por la sociedad?, ¿En qué medida puede un accionista, conforme la autonomía de la voluntad privada, renunciar a sus derechos? ¿Hasta qué punto el consentimiento del socio excluye la ilegalidad o inconstitucionalidad de la privación de un derecho concedido al socio? ¿Quién determina que una renuncia o derogación de un derecho de accionista es lesiva, nula o válida? ¿Pueden tutelarse derechos inderogables a los accionistas que renuncia a ellos ante fedatario público o se opone a su protección o preservación? ¿Qué debe prevalecer en el caso de que se disponga por asamblea del dividendo decretado, la decisión de la mayoría o el derecho del socio afectado? ¿Qué debe privilegiarse, la autonomía personal del socio o la defensa del orden constitucional, para determinar si un pacto estatutario lesiona o no los derechos fundamentales del accionista?

Para responder lo anterior, se clasifican los derechos de accionista en: a) Derechos esenciales o instrumentales, b) Derechos mínimos fundamentales 
DERECHO GLOBAL. ESTUDIOS SOBRE DERECHO Y JUSTICIA

(inderogables e indisponibles); y, c) Derechos disponibles (por la sociedad o por el socio).

\section{V.1 Derechos instrumentales}

Son derechos esenciales que corresponden en abstracto al accionista, que garantizan la efectividad de los derechos concreto de accionista, la subsistencia de los derechos mínimos y disponibles y la configuración del tipo social, por ello es necesaria su identificación.

Aunque hoy por hoy no es posible realizar un elenco exhaustivo de los derechos mínimos fundamentales del accionista, como se podía realizar con la S.A. moderna regulada desde hace más de doscientos años en el Código de Comercio francés, tales derechos están garantizados por otros derechos abstractos denominados instrumentales, que son el fundamento para el carácter de accionista y para la configuración del tipo social.

Son derechos instrumentales los siguientes:

a) Derecho de responsabilidad limitada, que es un derecho que tiene todo accionista de la S.A. de no responder por las deudas sociales y solo asumir una responsabilidad limitada al pago de sus aportaciones; este derecho garantiza además la configuración del tipo social de S.A., una sociedad en la que sus socios no responden de las deudas sociales y su obligación se limita a pagar sus acciones.

b) Derecho de permanencia, es uno de los derechos fundamentales e individuales por excelencia de los accionistas, que implica: i) derecho de permanecer como socio en las mismas condiciones que cualquier otro accionista, derecho que es conferido por una norma de derecho público no susceptible de limitación por acuerdo mayoritario; ii) derecho de permanecer en la sociedad como accionista, de no ser expulsado de la misma sino por las causas legales o estatutarias previamente establecidas y justificadas en el acto constitutivo social aceptadas por el accionista y conforme el procedimiento legalmente previsto; $y$, iii) derecho de permanecer en el mismo estatus, calidad o posición adquirida en la sociedad, sin alteración o conversión alguna salvo con su consentimiento y conforme las normas y procedimientos previamente establecidos por la ley o en 
los estatutos sociales aceptados; así como el derecho de separarse de la sociedad o dejar de ser socio mediante la enajenación de sus acciones conforme lo previsto en los estatutos sociales.

c) Derecho de Igualdad, todos los accionistas tienen los mismos derechos por cada acción de que sean titulares dentro de una misma clase. La S.A. es una sociedad capitalista en la que los derechos de los socios son medidos por el número de acciones que suscriben y no por el sujeto, a mayor aportación mayores derechos, pero éstos deben ser iguales en cada una de las acciones de cada clase. La sociedad debe dar un trato igual a los socios y también un trato igual a los que sean titulares de acciones que se encuentren en condiciones idénticas, vgr. un voto por cada acción ordinaria o un dividendo preferente igual a todos los titulares de acciones de voto limitado, por lo que la asamblea no puede atribuir mayores derechos a unos accionistas o eliminar, cambiar o convertir los derechos de otros, amortizar o reembolsar sus acciones a menos que sea conforme la ley, los estatutos, la clase acciones, o con el consentimiento de los afectados.

d) Derecho de proporcionalidad, los accionistas tienen derecho de recibir una participación en los beneficios sociales, utilidades, premios, cuota de liquidación y suscribir nuevas acciones en la proporción que corresponda de sus acciones con relación a la totalidad de las que integran el capital social, o la clase a la que pertenezcan; vgr las acciones de referencia conceden utilidades solo de un sector determinado de la sociedad, pero los titulares de esa clase de acciones tienen derecho a recibirlas en la proporción que les corresponda dentro de dicha clase. Salvo pacto en contrario, los accionistas tienen derecho a recibir dividendos en la proporción que guarde el monto exhibido de sus aportaciones con la suma del capital,

e) Derecho de acceso a la información y transparencia, es el derecho que se concede a todos los accionistas para acceder a la información de la sociedad y conocer sus operaciones, sus resultados y la actuación de los administradores, este derecho instrumental permite acceder a la revisión del balance, estados financieros y demás información a la que la ley se refiere, así como en su caso a ejercitar la acción de responsabilidad en contra de los administradores, entre 
otros.

f) Derecho de competir (a. 87 LGSM), aunque los socios pueden convenir no hacerlo (artículos 198 LGSM), bajo ciertos requisitos como los de tiempo, espacio, actividad y siempre que la sociedad no sea un agente económico con poder substancial en el mercado relevante de que se trate.

g) Derecho de agrupamiento, conforme el cual los accionistas tienen derecho de agruparse ya sea como minoría para hacer valer los derechos que la ley les concede para pedir convocatoria a asamblea en cualquier tiempo, para oponerse a los acuerdos de asamblea, para designar un consejero o un comisario, para exigir responsabilidad al órgano de administración, para unificar su voto, para celebrar pactos parasociales o para constituirse en minoría o mayoría. Estos derechos son la base sobre la que se sustentan los derechos mínimos fundamentales del accionista, el límite de la competencia de la sociedad y de la imposición de obligaciones a los accionistas.

\section{V.2. Derechos mínimos fundamentales del accionista}

Los derechos mínimos fundamentales del accionista (Tobío Rivas, 1995, pág. 20) son derechos que de suyo corresponden a todo accionista de la S.A. por tener tal carácter y que los distingue de los asociados, colaboradores, acreedores o partes de otros negocios jurídicos afines; son derechos inderogables, no pueden ser suprimidos por los estatutos ni la asamblea por desfigurar al accionista y a la S.A. Son llamados también derechos individuales o esenciales del accionista, se trata de derechos indisponibles por la sociedad e irrenunciables por su titular quien no puede renunciar a ellos, ni en el seno de la asamblea ni por acuerdos parasociales u otros convenios o estipulaciones, ya que son esenciales a la construcción del tipo societario (puede cederlo a un tercero pero no renunciar a ese derecho que de suyo lo tiene), por lo que en el caso de que se haga la renuncia, ésta no surte efectos y el accionista puede hacer uso de sus derechos (artículos 17 LGSM). Aunque inderogables son alterables por cuanto que la sociedad puede disminuir o aumentar la cuantía de los mismos, pero no los puede suprimir. En México, estos derechos se han reducido a su máxima expresión, no existe un listado legal de los derechos del accionista, ni una norma que prevenga que son numerus clausus o 
apertus (Duque Domínguez, 1994, pág. 37), o su configuración como derechos inderogables (Tobío Rivas, 1995, pág. 28), salvo respecto del derecho de las utilidades cuya privación a uno o más socios es nula (artículos 17 LGSM), pero se pueden mencionar como tales derechos mínimos fundamentales del accionista (Broseta Pont, 1990, pág. 236), sin los cuales la sociedad no existiría o sería leonina (De la Cámara Álvarez, 1997, pág. 34), los siguientes: de asistencia en asamblea, utilidades, información, separación, asignación gratuita de acciones (En los casos que correspondan, como en capitalización de primas de emisión, revaluación de activos o utilidades, así como en escisión o fusión por absorción) (Sánchez, 1984, pág. 90 y 102), derechos de minoría, cuota de liquidación, rendición de cuentas e impugnación; porque son los derechos mínimos que corresponden al socio como tal, que no pueden ser suprimidos aunque sí pueden ser alterados con su consentimiento desde que ingresa en la sociedad o con posterioridad, ya sea en asamblea o al suscribir ciertas clases de acciones.

Estos derechos mínimos han variado respecto de los del accionista de la S.A. moderna, porque se ha producido un cambio radical de la perspectiva del estatus de socio que se refleja en la supresión actual de los derechos de voto y de suscripción preferente que fueron considerados inderogables, y el primero de ellos como el mejor y mayor derecho de los de consecución de los accionistas, si bien el voto permanece aunque solo sea para la asamblea especial y en algunos países se recupera en el evento de que no se pague el dividendo preferente que confieren, pero esto no es una regla porque la tendencia actual es que ese dividendo sea estatutario y no legal, la ley no exige otorgar esa compensación por la privación del voto.

El Código de Comercio colombiano (arts. 371 y 381), reconoce como derechos esenciales del accionista, los derechos de deliberación, voto, utilidades, transmisión de acciones, de inspección de los libros y papeles sociales y, de cuota de liquidación. Los demás derechos (pero no los instrumentales) son derogables, disponibles y renunciables. Para la doctrina, se trata de derechos individuales, que se entrecruzan con los derechos de la sociedad, a fin de alcanzar la justicia en la participación (Mossa, 1957, pág. 296). Los derechos individuales son derechos adquiridos por los accionistas, que le pertenecen en tal calidad, que 
surgen de su participación en la sociedad y son independientes de los acuerdos y/o decisiones de la asamblea y del órgano de administración. Están contenidos en el ordenamiento jurídico por lo que sus órganos no pueden disponer de ellos, nacen del acto constitutivo social y no pueden ser derogados por la mayoría (Brunetti, pág. 526), porque son derechos individuales del accionista. Para la doctrina italiana, la característica del derecho individual radica en no estar nunca y en ningún caso sujeto a la voluntad de la mayoría una vez que se ha otorgado al accionista, le pertenece exclusivamente por el hecho de serlo, quedando excluidos otros derechos que puede tener por otra circunstancia. Se sostiene que la sociedad no puede eliminar esos derechos ni por principio de mayoría ni modificando los estatutos; por ello, el accionista tiene acción para exigir que sea reintegrado en su ejercicio y en su caso para el resarcimiento sobre el valor del activo social para el reembolso de acciones, cuando no es posible aquél, como en los supuestos de violación a los derechos de voto, deliberación, separación.

La nota que distingue estos derechos individuales es la falta de legitimación de la mayoría en la asamblea o del órgano de administración para excluir el derecho o para limitarlo más allá de los límites legales; por tanto, si ese derecho se sustrae a la voluntad de la asamblea es un derecho individual del accionista, un derecho adquirido de manera absoluta; pero si tales derechos pueden ser limitados o suprimidos por la asamblea, entonces serán derechos adquiridos de manera relativa.

Esta teoría de los derechos individuales (derechos propios o derechos adquiridos) de los accionistas, a decir de Duque Domínguez (Duque Domínguez, 1994, pág. 50 y 51) corresponde a la visión de que la sociedad y sus socios son personas substancialmente distintas y opuestas, pero fue superada de alguna manera desde la exposición de Gierke Julios Von de su teoría sobre la naturaleza de la sociedad, en donde los intereses de ésta y de sus socios quedan englobados en la unidad de la sociedad, en la que el interés de accionista se realiza en la esfera de intereses comunes, dado que la realización del interés de la sociedad lleva aparejada la realización del interés de los accionistas, por lo que, según dicho autor, no hay necesidad de conceder al accionista derechos individuales, pues la concesión de sus derechos propios no es para proteger sus intereses 
personales sino para promover el interés común de la sociedad, que los mismos poseen dimensión social y no individual; de ahí que se discuta si tales derechos individuales son derechos inderogables por la asamblea general, invulnerables a la decisión de la asamblea que no puede suprimirlos ni limitarlos, e irrenunciables porque los accionistas no pueden renunciar en absoluto o abstracto a los mismos aunque sí en concreto.

Derivado de lo anterior se cuestiona si tales derechos son del accionista y por tanto solo protegen su esfera de libertad, que no puede ser invadida por acuerdos mayoritarios de la asamblea ni por el órgano de administración (teoría individualista), sin que ello implique estar habilitado para exigir cualquier prestación a la sociedad; o si se trata de derechos de sujetos que despliegan una actividad en el órgano societario y entonces, son derechos en interés de la sociedad, derechos de corte colectivo y por tanto se conceden al accionista para controlar la administración de la sociedad, conservar el patrimonio y obtener el fin social para el cual se constituyó la sociedad pero no en su provecho individual; en este segundo supuesto, el accionista no se considera como individuo sino como parte de una sociedad para la cual realiza una función (teoría funcional) mediante el ejercicio de ciertos poderes que se le conceden para tutelar y promover los intereses sociales.

Para determinar cuáles son esos derechos individuales, o adquiridos, del accionista, se han esbozado dos teorías, la de la confianza y la de la base del negocio, conforme la primera, atribuida a Lehmann, esos derechos son los que para el accionista medio son de tal importancia que de no concederlos no habría participado en la sociedad. La teoría de la base del negocio, sostenida por Wieland, postula que son derechos del accionista aquellos cuyo ejercicio legitima los principios fundamentales de la sociedad, particularmente el de igualdad de trato de todos los accionistas y los de participación en la administración y en los beneficios. Para Brunetti, tiene tal carácter los derechos: de permanencia; de limitación de responsabilidad, de obtener documento de legitimación, de voto, de receso, dividendo, impugnación, aumentos de capital y de liquidación (Brunetti, pág. 527). Son derechos inderogables, los derechos mínimos que la ley o los estatutos otorgan a los accionistas en lo individual, que no se pueden suprimir, 
aún y cuando no los califique expresamente de esa manera; se trata de derechos que no pueden ser eliminados, alterados o modificados en perjuicio de los accionistas por la asamblea, por el órgano de administración, o por los estatutos, aunque algunos de ellos pueden ser modificados solo con el consentimiento de los titulares de esos derechos.

Son derechos que le corresponden al accionista como tal, sin contrariar al orden público ni a las normas substancialmente imperativas del tipo social como las califica Paz-Ares (Paz-Ares Rodríguez J. C., 2011, pág. 4 y ss.), quien sostiene que el límite para determinar la validez queda reservado a la imperatividad sustantiva que se basa en la defensa de los valores centrales o fundamentales del derecho privado (por ejemplo, interdicción de la usura (pactos leoninos), causalidad de la atribución, revocabilidad de los poderes, no exención de la responsabilidad por dolo, etc.), que no basta la imperatividad tipológica o de ius cogens a que se refería Girón Tena, que solo viene establecida en el derecho de sociedades por la necesidad de estandarizar un modelo societario al objeto de cambio, mientras que las normas de ius imperativum imponen una valoración de la regla negocial a la luz del sistema jurídico entero y, por tanto, establecen una relación entre inderogabilidad y principios fundamentales del sistema jurídico que no existe en las normas de ius cogens, que se extienden a todos los tipos sociales y al derecho de las obligaciones y que son los únicos límites a los pactos parasociales, pero los pactos parasociales solamente son exigibles en principios entre quienes lo celebraron siempre y cuando no contraríen los principios configuradores del tipo social, las normas imperativas de organización y funcionamiento y los límites a la autonomía de la voluntad negocial.

Estos derechos se sustentan en las bases esenciales de la sociedad, son el fundamento mismo del tipo social y del vínculo social, afectan la esencia y la estructura orgánica de ente social por lo que no pueden ser derogados. Para Girón Tena los derechos a las utilidades, al voto, asistencia, suscripción preferente, información y de agrupación son inderogables (Girón Tena, 1952, pág. 181).

Estos derechos son además irrenunciables, como los derechos de asistencia, de asignación gratuita de acciones emitidas por aumento del capital por capitalización de reservas de valuación, revaluación, primas de acciones y de 
reservas utilidades distribuibles (artículos 116 LGSM), el derecho de información, los derechos de separación y de retiro, el derecho de celebrar pactos con otros socios o terceros, el derecho de impugnación y el derecho de hacerse representar.

Para Tobío Rivas, estos derechos pueden ser objeto de exclusiones o limitaciones por la propia ley, como el de voto y de utilidades cuando el accionista tiene un interés contrario o no cumple con la exhibición de sus acciones en los plazos pactados, así la LSA española suspende los derechos de voto, de dividendos y de suscripción preferente en caso de acciones pagadoras, y en México, aunque el socio mantiene todos sus derechos incólumes, el de utilidades solo puede hacerlo efectivo en la proporción que efectivamente haya desembolsado por cada acción pagadora; así también la suspensión del derecho de voto se presenta en el caso de que la sociedad haya adquirido acciones propias, en tanto pertenezcan a la sociedad, o la posibilidad de emitir acciones sin derechos de voto o con otras limitantes; por último el derecho de suscripción preferente puede ser suprimido, limitado o suspendido pero en todo caso una vez concedidos no se pueden eliminar a menos que se den los supuestos mencionados.

\section{V.3. Derechos disponibles}

Son los derechos que la ley y los estatutos confieren a los accionistas, pero la asamblea puede disponer de ellos, unas veces con consentimiento de su titular, otras con el del grupo al que pertenece y otras más sin dicho consentimiento; y, se incluyen también los llamados derechos renunciables. Algunos autores (De la Cámara Álvarez, 1997, pág. 572) aluden a a derechos irrenunciables o irrevocables y derechos renunciables, siendo los primeros aquellos que no se pueden suprimir ni por acuerdo mayoritario, ni con el consentimiento o voluntad del accionista, ya que no son disponibles por éste, por tratarse de derechos concedidos no solo en su interés exclusivo, sino en interés de la propia sociedad, esenciales para su tipología social (Girón Tena, 1952, pág. 181).

En México, ningún acuerdo mayoritario puede hacer perder a un socio su carácter, ya que la sociedad está obligada a reconocerlo como socio “...y no puede por si misma desconocer tal obligación, sin violar el art. 1797 del C.C., interpretado extensivamente" (Mantilla Molina, 1996, pág. 221) a menos 
que conforme los estatutos aceptados el accionista sea expulsado de la sociedad; porque al ingresar a la sociedad al socio lo mueve un fin determinante de su voluntad (causa en el sentido de la técnica jurídica), por lo que se obliga a realizar una aportación y la realiza parcial o totalmente; ese motivo es, normalmente, la obtención y reparto de utilidades; por lo que la sociedad no puede privarle de ellas, porque equivaldría a dejar sin causa la obligación del socio, que incluso puede haber sido ya cumplida (Mantilla Molina, 1996, pág. 221). Para precisar cuáles son esos derechos disponibles, es necesario determinar los límites de la facultad de la asamblea para modificar o suprimir sin causa, culpa o responsabilidad del accionista, sus derechos; si ello es posible a la luz del interés de la sociedad o si en todo caso deben respetarse los derechos individuales del accionista, que mientras no otorgue su consentimiento no pueden ser modificados; es decir, mientras no renuncie a su derecho, no puede ser privado del mismo; pero la cuestión es difícil porque por un lado el accionista que por lo general, conforme su propio instinto de conservación e interés opuesto buscará los mejores provechos y las menores cargas y no estará dispuesto a renunciar a los derechos adquiridos como accionista, o no cuando menos de manera gratuita, al tiempo que el interés social o el de los demás accionistas buscará despojarlo o alterarlo en sus derechos o privilegios; en México, conforme la LGSM, la asamblea general es el órgano supremo que como tal puede adoptar cualquier acuerdo, incluso sobre la modificación de los derechos de cierta clase de accionistas, pero en este caso, exige que cualquier proposición que la pueda perjudicar sea previamente aceptada por dicha clase reunida en asamblea especial, en la que se requiere la mayoría calificada de cuando menos el cincuenta por ciento, computado con relación al número total de acciones de la clase de que se trate; de manera que sí bien se necesita el consentimiento del socio, no lo es individual sino agrupado, por mayoría.

La afectación de los derechos de socio que no configura una clase especial solo se puede llevar a cabo cuando la ley la autoriza, como la amortización de acciones con utilidades repartibles mediante sorteo o la reducción generalizada por reembolso de acciones, actos que desde luego pueden implicar que uno o más socios pierdan tal carácter o disminuyan su porcentaje accionario y por tanto que se altere su situación de socio, por lo que en todo caso se deben respetar los derechos fundamentales de permanencia e igualdad que exigen un trato igual a 
todos los accionistas, por lo que la misma LGSM previene que la amortización se lleve a cabo mediante sorteo (artículos 136). También la LGSM prevé la posibilidad de excluir al accionista y privarlo totalmente de su estado de socio, ya sea por no pagar sus acciones o por incurrir en alguno de los supuestos que deben estar especialmente previstos en los estatutos sociales; fuera de esos casos, salvo que los estatutos o la clase de acciones que se emita, la asamblea general carece de facultades y competencia para alterar el estado de socio y particularmente para disponer de los derechos del accionista; el art. 195 garantiza no solamente el derecho de audiencia a los titulares de la clase de acciones de que se trate, sino también sujeta la disponibilidad del derecho de clase al consentimiento de dicha clase adoptado por mayoritaria calificada; lo que desde luego garantiza la permanencia de derechos de las clases de accionistas y también da pauta para que dicha clase condicione de algún modo a la sociedad, la aceptación de la variación de sus derechos, de donde resulta que la ley privilegia el fin social sobre el individual del accionista, aunque podría ser solo en interés de la mayoría que puede abusar de la minoría.

La Companies Act de 2006, art. 630, ha previsto que se pueden variar los derechos de clase a) cuando los estatutos establezcan esa posibilidad y conforme lo señalado en los mismos o, b) cuando los estatutos nada digan pero los titulares de la clase de acciones de que se trate otorguen su consentimiento por escrito de por lo menos las tres cuartas partes del valor nominal de las acciones emitidas de esa clase (con exclusión de cualesquiera acciones en autocartera), o c) por resolución especial aprobada en una asamblea especial de los tenedores de esa clase. Lo que parece constituir una buena medida de protección a los accionistas respecto de sus derechos adquiridos, si bien en lo individual tendrán que someterse a la decisión de la mayoría de los de su misma clase. Esta situación difícil pero entendible para quienes forman parte de una sociedad, obviamente surge en los casos en los que la variación de los derechos es para colocar a los accionistas en una situación inferior a la que tienen en la sociedad; esto es, para disminuir de algún modo sus derechos, puesto que si es para mejorarlos no hay perjuicio para esa clase especial de accionistas, aunque puede existir para los demás accionistas.

Salvo que exista una causa justificada en interés de la sociedad, o una 
condición cumplida, un supuesto previsto en estatutos, un incumplimiento del accionista, o su consentimiento otorgado desde la constitución de la sociedad o la suscripción de acciones que establezcan de antemano la alteración o supresión de sus derechos, o que con posterioridad en asamblea en general o especial el accionista haya aceptado dicha alteración; la sociedad no puede privar, o limitar arbitraria o unilateralmente los derechos adquiridos del accionista; debe existir una causa suficiente y razonada que permita válidamente suprimir o alterar el estado de socio. Lo anterior, a pesar de que las leyes contemporáneas permiten adoptar acuerdos sobre modificaciones de los estatutos por mayoría calificada, en las que se incluyan cláusulas estatutarias que alteren los derechos de los accionistas en su perjuicio; pero esa modificación no puede perjudicar los derechos adquiridos del socio, vgr. con relación a la supresión o suspensión del derecho de suscripción preferente, que la actual LGSM permite incorporar en los estatutos sociales, pues si bien se prevé en el art. 91 esta posibilidad, para los estatutos sociales fundacionales, nada impediría que se reconozca ese derecho a la asamblea mediante una reforma estatutaria siempre y cuando sea aceptada por unanimidad; aunque en ciertos países se concede un plazo para que accionista ejercite su derecho de separación en caso de no estar conforme con dicha reforma y en su defecto se le obliga en los términos de la reforma realizada.

Respecto de la disponibilidad de los derechos con el consentimiento del accionista, aunque existe una amplia libertad contractual en materia societaria según lo dispuesto por el art. $8^{\circ}$ de nuestra LGSM, cuando se refiere a que las normas permisivas no limitan la autonomía de la voluntad, se debe indagar cuáles son los derechos disponibles y por tanto renunciables conforme las normas de dicha ley, del Código de Comercio y del Código Civil Federal, porque aquella autonomía no escapa a los límites previstos por estos códigos que reconocen la libertad de las personas para realizar actos y negocios jurídicos y para incluir en ellos las cláusulas que consideren más convenientes, siempre que no contravengan el orden público, las leyes prohibitivas, la moral, las buenas costumbres y los derechos de tercero, límites en salvaguarda de los derechos de la sociedad y de los terceros. Asimismo, aunque el art. 196 de la LGSM sólo restringe el derecho de deliberación en el caso de que exista un interés contrario a la sociedad, el art. 
91, Fr VII de la misma LGSM permite disponer de ese derecho y diversos arts. de la LGSM se refieren tácita pero claramente a la posibilidad de disponer de ciertos derechos considerados otrora como inderogables e irrenunciables, vgr. el derecho de un voto por cada acción. De lo que sigue es que el accionista puede renunciar a sus derechos de socio siempre y cuando los mismos sean derechos privados, disponibles, subjetivos, potestativos y patrimoniales en el sentido de susceptibles de una valoración económica y no de la clase de derechos a que se refiere la doctrina, porque el voto aunque está catalogado como el derecho por excelencia de consecución o corporativo, tiene también un valor de cambio, es valorable en dinero y en ese sentido es un derecho patrimonial; el art. 2209 del Código Civil Federal señala que cualquiera puede renunciar a su derecho y remitir, en todo o en parte, las prestaciones que le son debidas, excepto en aquellos casos que la ley lo prohíba. Los derechos inderogables y los instrumentales no son renunciables, además, la renuncia debe ser clara, precisa y que no deje lugar a dudas del derecho al que se renuncia. Así, en una tesis aislada se ha sostenido que la renuncia de derechos privados solo es válida cuando no afecta el interés público ni perjudica el de terceros, por ser principio jurídico reconocido que la voluntad de las partes, es la suprema ley de los contratos (Renuncia de derechos privados. No es válida si se afectan los de terceros y el interés público, y si no se establece en términos claros y precisos (interpretación del artículo 6o. Del Código Civil para el Distrito Federal, Décima Época, Libro 19, Tomo III).

NORMAS SUSTANTIVAS CIVILES. PUEDEN SER OBJETO DE RENUNCIA SI NO SE AFECTA EL INTERÉS PÚBLICO NI DERECHOS DE TERCEROS. El artículo 6o. del Código Civil para el Distrito Federal consagra los principios de imperatividad plena y total, y de irrenunciabilidad de la ley, estableciendo que la voluntad de los particulares no puede eximir de la observancia de ella, ni alterar o modificar las normas, salvo que se trate de la renuncia de derechos privados que no afecten directamente el interés público y no perjudique derechos de terceros. Disposición que interpretada armónicamente con el principio jurídico plasmado en el artículo 1796 de ese ordenamiento legal, en el sentido de que la voluntad de las partes es la ley suprema de los contratos, permite arribar a la convicción de que es posible renunciar válidamente a los derechos sustantivos, con la condición de que esa dimisión no afecte el interés público ni perjudique derechos de terceros. Además, 
si bien el artículo 8o. de tal codificación establece como regla general que "los actos ejecutados contra el tenor de las leyes prohibitivas o de interés público serán nulos", admite en su propio texto como excepción "los casos en que la ley ordene lo contrario", lo que encuentra congruencia y también sustento en el artículo 2209 de ese código que prevé que cualquiera puede renunciar su derecho y remitir, en todo o en parte, las prestaciones que le son debidas, excepto en aquellos casos en que la ley lo prohíba (Normas sustantivas civiles, Tomo XVII, ).

En el caso de los derechos de accionistas, la renuncia puede ser total o parcial; son derechos renunciables entre otros: i) totalmente: dividendo preferente, el voto y la suscripción preferente; ii) parcialmente: dividendos, cuota de liquidación, retiro y enajenación de acciones

\section{Conclusiones}

Los accionistas de una S.A. gozan de diversos derechos que les permiten tener injerencia directa o indirecta en la administración, en el control de la gestión social, en las decisiones y en las utilidades de la sociedad, conforme la clase de acciones de que sean titulares y los derechos mínimos fundamentales de todo accionista que le garantizan un trato igual, equitativo, proporcional y conforme a las normas imperativas y configurativas del tipo social de S.A. La desregulación societaria y la flexibilización, como fenómenos facilitadores de la constitución y funcionamiento de la sociedad han privilegiado a la autonomía de la voluntad de los socios en la determinación de sus derechos y obligaciones con la S.A., al punto que diversos derechos considerados inderogables en la S.A. moderna se han transformado por la ley en derechos suprimibles y disponibles y con ello puesto en predicamento diversos principios de la sociedad anónima; sin embargo, los accionistas conservan un conjunto de derechos mínimos fundamentales que no pueden ser derogados y que tienen derecho a conservar para la subsistencia de tal carácter y la causa del negocio social que es la vocación a ganancias y pérdidas, pues de otra forma no se tratará de un accionista sino de un obligacionista o acreedor social. La nueva tendencia de la S.A. que privilegia 
las normas permisivas y en general la autonomía de la voluntad en materia societaria ha de verse como una nueva adaptación de la S.A. hacia una sociedad contemporánea que responde a las exigencias de la economía y las tendencias mundiales, pero no como un mecanismo de abuso de las mayorías o de la minoría unificada en perjuicio de los demás accionistas ni como un instrumento que altere los elementos mínimos configurativos de la sociedad y del accionista, para lo cual es necesario identificar y precisar los derechos instrumentales y los mínimos fundamentales del accionista.

\section{Bibliografía}

Acciones de compañias, derechos provenientes de las, 1145/42 (3a Sala, Suprema Corte de Justicia de la Nación 22 de abril de 1942).

Barrera Graf, J. (1983). Las Sociedades en Derecho Mexicano. México: Universidad Nacional Autónoma de México.

Broseta Pont, M. (1990). Manual de Derecho mercantil ( $8^{\mathrm{a}}$ ed.). Madrid, Madrid, España.

Brunetti, A. (s.f.). Tratado de sociedades (Vol. T. II). (F. d. Cañizares, Trad.) Argentina: UTEA.

Castro Ossandon, H. (1985). Estatuto del accionista. Chile, Chile, Chile: Editorial jurídica de Chile.

De la Cámara Álvarez, M. (1997). Estudios de derecho Mercantil (2a ed., Vol. I). Madrid.

Duque Domínguez, J. F. (1994). "Protección de los derechos del accionista". En A. (. Alonso Ureba, Derecho de Sociedades Anónimas (pág. 35). Madrid, Madrid, España: Civitas.

Fernández Villamayor, Á. (1978). El Régimen legal de la sociedad anónima en Chile. Editorial Jurídica de Chile.

Galgano, F. (1984). La Società per azioni”, Trattato di Diritto Commerciale e di Diritto Pubblico dell'economia (Vol. VII). Padua, Italia.

Garrigues, J. (1981). Curso de derecho mercantil. México, México, México: Porrúa. 
Girón Tena, J. (1952). Derecho de Sociedades Anónimas. Madrid, España: Universidad de Valladollid.

Malagarriga, C. (1951). Tratado Elemental de Derecho Comercial, (Vol. T. I). Buenos Aires, Argentina.

Mantilla Molina, R. L. (1996). Derecho mercantil (29a ed.). México, México, México: Porrúa.

Messineo, F. (1955). Manual de Derecho Civil y Comercial (Vol. IV).

(S. S. Melendo, Trad.) Buenos Aires, Buenos Aires, Buenos Aires: Ediciones Jurídicas Europa-América,.

Mossa, L. (1957). Tratato del Nuovo Diritto Comerciale (Vol. IV Società per azioni). Padua, Italia.

Normas sustantivas civiles, Tesis: I.3o.C.408 C(Novena Época, Tribunales Colegiados de Circuito, Semanario Judicial de la Federación y su Gaceta Junio de 2003, p. 1028 de Tomo XVII, ).

Paz-Ares Rodríguez, J. C. (1996). ¿Dividendos a cambio de votos? ,1996. Madrid, España: Mc Graw Hill.

Paz-Ares Rodríguez, J. C. (2011). La validez de los pactos parasociales". La Ley (en línea)(no 7714).

Pérez Fontana, S. ( 1983). Manual de sociedades comerciales. F.C.U.

Renuncia de derechos, Tesis: I.3o.C.193 C (10a.) (Tribunales Colegiados de Circuito, Gaceta del Semanario Judicial de la Federación p. 2385 de Junio de 2015 de Décima Época, Libro 19, Tomo III).

Rodríguez Rodríguez, J. (1982). Curso de derecho mercantil (16a. Ed. ed.). México, México, México: Porrúa.

Rubio, J. (1974). Curso de sociedades anónimas ( $3^{\text {a }}$ edición ed.). Madrid, Madrid, España: Edersa.

Sánchez, A. (1984). Las acciones, la acción y los derechos del accionista (artículos 57 a 50 LSA). En U. R. Mnauel, Compendio al Régimen Legal de las sociedades mercantiles (Vols. 1, t. IV,). Madrid, España: Civitas.

Tobío Rivas, A. M. (1995). Limitaciones de los derechos de asistencia y voto del accionista (artículos 105 LSA). Civitas.

Vicent Chuliá, F. (1991). Compendio crítico de derecho mercantil (3a ed., Vols. T.I, Vol. I). Barcelona, Barcelona, España. 